\title{
BİST'te Hisse Senetleri İşlem Gören Otomotiv Sektöründeki Firmaların TOPSIS Yöntemine Göre Performans Değerlemesi ve Analizi ${ }^{1}$
}

\author{
Cevdet A. Kayalıa İsmail Aktaş ${ }^{b^{*}}$ \\ aİmir Demokrasi Üniversitesi, İktisadi ve İdari Bilimler Fakültesi, İzmir. \\ ${ }^{b}$ Çanakkale Onsekiz Mart Üniversitesi, Çanakkale.
}

\section{$\ddot{O} z$}

Bu çalışmada, Borsa İstanbul (BISST)'da hisse senetleri işlem gören otomotiv sektöründe faaliyet gösteren 7 şirketin 2010-2015 yılları arasındaki finansal tablolar ve faaliyet raporları kullanilarak finansal oranlar belirlenmiştir. Bu finansal oranlar çok kriterli karar verme yöntemlerinden biri olan TOPSIS yöntemi kullanilarak incelenmiştir. TOPSIS yöntemi yardımıyla belirlenen finansal oranlar tek bir puana çevrilmiştir. Bu aşamanın devamında TOPSIS yöntemiyle elde edilen veriler en yüksek puandan başlayarak sıralanmıştır. Çalışmanın sonucunda bazı şirketlerin finansal performans sıralamasını istikrarl bir şekilde koruduğu, kalan diğer şirketlerin ise siralamadaki yerinin değişkenlik gösterdiği görülmüştür. Şirketlerin sıralamasındaki değişkenliklerin nedenleri finansal performansla olan ilişkisi incelenmiştir. Bu çalışmanın amacı Türkiye otomotiv sektöründe faaliyet gösteren ve hisse senetleri BİST'te işlem gören 7 otomotiv şirketinin 2010-2015 yılları arasındaki finansal performansını çok kriterli karar verme yöntemlerinden biri olan TOPSIS yöntemi ile incelemek ve sonuçlarını değerlendirmektir.

Anahtar Kelimeler: Otomotiv Sektörü, Finansal Performans, TOPSIS Yöntemi.

\section{Performance Evaluation and Analysis through the TOPSIS Method of Firms in the Automotive Sector Trading in BIST}

\begin{abstract}
In this study, the financial ratios of the 7 companies operating in the automotive sector whose stocks are traded in Stock Exchange Istanbul (BIST) were determined by using financial statements and activity reports between 2010-2015. These financial ratios were examined through the TOPSIS method, which is one of multi-criteria decision making methods. The financial ratios determined by the TOPSIS method have been converted into a single score. In the following of this phase, the data obtained by the TOPSIS method are ordered starting from the highest score. As a result of the study, it is seen that some companies keep their financial performance ranking steadily, while the rest of the companies show varying place in the order. The relationship between sequential variability of firms and their financial performance is examined. The aim of this study is to examine the financial performance of 7 automotive companies operating in Turkey's automotive sector and traded in BISST through the TOPSIS method which is one of the multi criteria decision making methods and to evaluate the results
\end{abstract}

Keywords: Automotive Sector, Financial Performance, TOPSIS Method.

\section{GíRiş}

Gelişen ve değişen dünyada otomotiv sektörü önemli bir role sahiptir. Otomotiv sektörü, ülkelerin ekonomik anlamda büyümesine ve gelişmesine katkı sağlarken diğer sektörlerle de yakın ilişki içindedir. Birçok sektörün ürettiklerinden faydalanır; demir-çelik, cam, plastik, tekstil, elektrik ve elektronik sektörleri bunların başında gelir ayrıca bu sektörlerin gelişmesine yardımcı olur (Karbuz vd., 2008: 3-4). 
Bunların yanında otomotiv sektörü, yedek parça gibi diğer yan sanayi kuruşlarına, üretilen araçların tüketiciye ulaşmasında katkıda bulunan ve satış sonrası hizmet veren sektörlere de istihdam yaratmaktadır.

Küreselleşen dünyada şirketlerin yaşamlarını sürdürebilmesi, kar edebilmesi, devamlılığı sağlayabilmesi ve rakipleriyle yarışır düzeyde olabilmesinde finansal performansın önemi büyüktür. Finansal performans, şirketlerin finansal verilerinden yararlanarak ölçülebilir sonuçlar ortaya çıkaran, şirketlerin olumlu ve olumsuz yanlarını gösteren ölçme aracıdır. Şirketler, finansal tablolar aracılığıyla belirlenen rasyolar (oranlar) yardımıyla finansal performansını ölçmeye çalışmaktadır. Finansal performans, şirketler için belirlenen hedeflere ne kadar ulaşıldığııı ve aksayan tarafların neler olduğunu gösteren bir geri bildirim aracıdır.

Mali tablolarda yer alan iki kalem arasındaki ilişkinin basit matematiksel ifadesine rasyo (oran) denilmektedir. Mali tablolarda yer alan kalemler arasinda basit matematik ilişkileri göstermek, başka bir deyişle rasyolar (oranlar) hesaplamak tek başına bir amaç değildir. Önemli olan hesaplanan rasyoların (oranların) yorumlanması ve değerlendirilmesidir (Akgüç, 1995: 345). Bu çalışmanın analizinde kullanılmak üzere seçilen oranlar, şirketlerin faaliyetlerine sürdürmelerinde, sahip oldukları varlıkların nasıl kullandıklarını ve karlılıklarını test eden rayoslardan (oranlardan) oluşmaktadır.

Likidite analizlerinde, işletme sermayesinin yeterlilik seviyesi düzeyi ve işletmenin kısa vadeli borç ödeme gücü araştırılır. Bu amaçla işletmenin dönen varlık ve kısa vadeli yükümlülükleri arasındaki anlamlı ilişkiler kuran oranlardan faydalanılır (Karapınar ve Zaif, 2013: 207). Likidite oranları cari oran, asit test oranı, stok bağımlılık oranı, nakit oranı ve hazır değerler oranlarından oluşmaktadır. Çalışmada likidite oranlarından cari oran kullanılmıştır.

Mali yapı analizlerinde, işletmenin öz kaynağının yeterli olup olmadığı, kaynak yapısı içinde borç ve öz kaynağın dengesi ve öz kaynak olarak yaratılan fonların ne tür dönen varlık ya da duran varlıklara kullanıldığının ölçülmesinde kullanılan oranlardır (Akdoğan ve Tenker, 1997: 537). Finansal yapı ile ilgili oranların belli başlıları olarak, kaldıraç oranı, öz kaynak oranı ve öz kaynağın borçları oranı sayılabilir (Haftacı, 2009: 90). Çalışmada mali yapı oranlarından toplam borç/toplam varlık oranı, öz sermaye/toplam varlık oranı ve kısa vadeli yabancı kaynak/toplam borç oranı kullanılmıştır.

İşletmenin çalışma durumu analizinde, işletme faaliyetlerinde kullanılan varlıkların etkili bir biçimde kullanılıp kullanılmadığını ölçmekte olan oranlara faaliyet oranları denilmektedir. Bu grupta yer alan oranlar ise stok devir hızı, alacak devir hızı, dönen varlıklar devir hızı, duran varlıklar devir hızı, aktif devir hızı, öz sermaye devir hızı ve maddi duran varlık devir hızıdır (Akdoğan ve Tenker, 1997: 543). Çalışmada stok devir hızı kullanılmıştır.

Karlılık oranları ise işletmelerin emrine verilmiş bulunan öz sermaye ve yabancı kaynakların, verimlendirme derecesinin ölçümünde kullanılmaktadır. İşletmelerin elde 
ettiği karın ölçülü ve yeterli olup olmadığının saptanmasında kullanılan oranlardır (Akdoğan ve Tenker, 1997: 593). Kar ile satışlar arasındaki ilişkiyi gösteren oranlar brüt satış karı/net satışlar oranı, faaliyet karı/net satışlar oranı, net kar/net satışlar oranı vb. kar ile sermaye arasındaki ilişkiyi gösteren net kar/öz kaynak oranı, net karın toplam varlıklara oranı, faaliyet karının net satışlara oranı vb. bunlara ilaveten de kar ile iş gücünün verimliliği arasındaki ilişkiyi ortaya koyan oranlar da çalışan kişi başına düşen net satışlar oranıdır (Akdoğan ve Tenker, 1997: 571). Çalışmada karlılıkla ilgili olarak net kar/öz sermaye oranı, net kar toplam varlık oranı, brüt satış karı/net satışlar oranı, faaliyet karı/net satışlar oranı ve çalışan kişi başına net satışlar kullanılmıştır.

Otomotiv sektöründeki faaliyet gösteren şirketler, diğer şirketler gibi finansal performanslarını değerlendirmesi hem yerel hem de küresel anlamda daha rekabetçi ve günün koşullarına uyum sağlayabilme bağlamında önemi büyüktür. Günümüzde şirketleri değerlendirirken sadece finansal tablolardan elde edilen oranların kullanılması yeterli değildir. Finansal oranlar şirketlerin mevcut ekonomik durumunu gösterirken, hedefledikleri diğer amaçları yorumlamakta eksik kalabilir. Türkiye'de otomotiv sektöründeki şirketlerin, üretilen ürünlerin kalitesi, pazar fırsatları ve sahip olunan insan gücünü iyi değerlendirerek belirlenen hedeflere ulaşabilmesi için finansal performansı göz ardı etmemelidir. Bunu ortadan kaldırabilmek için çok çeşitli karar verme süreçleri geliştirilmiştir.

\section{DÜNYADA ve TÜRKIYYE'DE OTOMOTIV SEKTÖRÜ}

18 yy. ilk motorlu aracın icadı ile başlayan otomotiv sektörü, hızlı bir şekilde gelişmiştir. Günümüzde otomotiv sektöründe 20'ye yakın ülkede üretim yapan 50 adet motorlu taşıt üreticisi bulunmaktadır. Motorlu taşıt üretimi otomobil ve ticari araç olarak ikiye ayrılmaktadır. Dünya otomotiv sektöründe, otomobil ve kamyonetlerden oluşan hafif araç üretimi yüzde 90 gibi önemli bir paya sahiptir. Geri kalan yüzde 10 kısmı ise Minibüs, midibüs, otobüs, kamyon, çekici gibi diğer araç sınıfların kapsamaktadır.

Büyük yatırımların yapıldığı dünya otomotiv sektörüne, Ar-Ge ve üretim anlamında yılda 90 milyar dolar düzeyinde yatırım harcaması yapılmaktadır. 2 trilyon dolar düzeyinde cirosu bulunan otomotiv sektöründen elde edilen vergi geliri ise 450 milyar doların üzerindedir. Bu verilere göre, otomotiv sektörü dünyanın sayılı ülke ekonomilerine karşılık gelmektedir. Dünya ekonomisinde önemli bir paya sahip olan otomotiv sektörü 8 milyondan fazla doğrudan istihdam yaratmaktadır. Bu rakam dünya imalat sektörü istihdamının da yüzde 5'inden fazladır. Bunun yanında dolaylı olarak dünya otomotiv sektörü kendisi ile birlikte 50 milyondan daha fazla kişinin istihdamına da katkı sağlamaktadır (Sanayi Genel Müdürlüğü, 2014: 8).

Türkiye'de 1960'lı yıllarda temelleri atılan otomotiv sanayisi ilk yıllarda kendi yerli otomobil üretim çabalarının yanında yabancı araçların ithalatı ve üretimine de gerçekleşmiştir. Bu dönemde ayrıca yedek parça ihtiyacını karşılama amacıyla da otomobil yan sanayisinin geliştiğini görmekteyiz. 1980 sonrası yapılan teknoloji yatırımları ile gelişen otomotiv sektörü yurt dişına araç ihraç etmeye başlamıştır. 1990'lı yıllarla birlikte Avrupa ile yapılan gümrük birliği anlaşması sonucunda 
Türkiye'ye yabancı yatırımcının ilgisi artmıştır. Kurulan modern üretim tesislerin yanında üretimin kalitesi de yükselmiştir. 2000'li yıllarla birlikte Türkiye otomotiv sektörü küresel anlamda tam entegrasyonun tamamlandığı ve teknolojik yatırımların yapıldığı bir dönem olmuştur. 2000 ile 2014 yılları arasında küresel motor üreticilerinin yapmış oldukları bu yatırımlar, Türkiye'deki üreticilerin imalat yeteneklerini önemli ölçüde geliştirerek ve Türkiye'nin küresel motorlu araç üretiminde katkıda bulunarak uluslararası role sahip olmasına yardımcı olmuştur. Türkiye otomotiv sektörü uluslararası güvenlik ve kalite standartlarını karşılayan üretimin yanında üretim kalitesi anlayışında küresel olarak rekabet edilebilir konuma gelmiştir. Grafik 1'de Dünya ve Türkiye'deki 2015 yılı motorlu araç üretim miktarları verilmiştir.

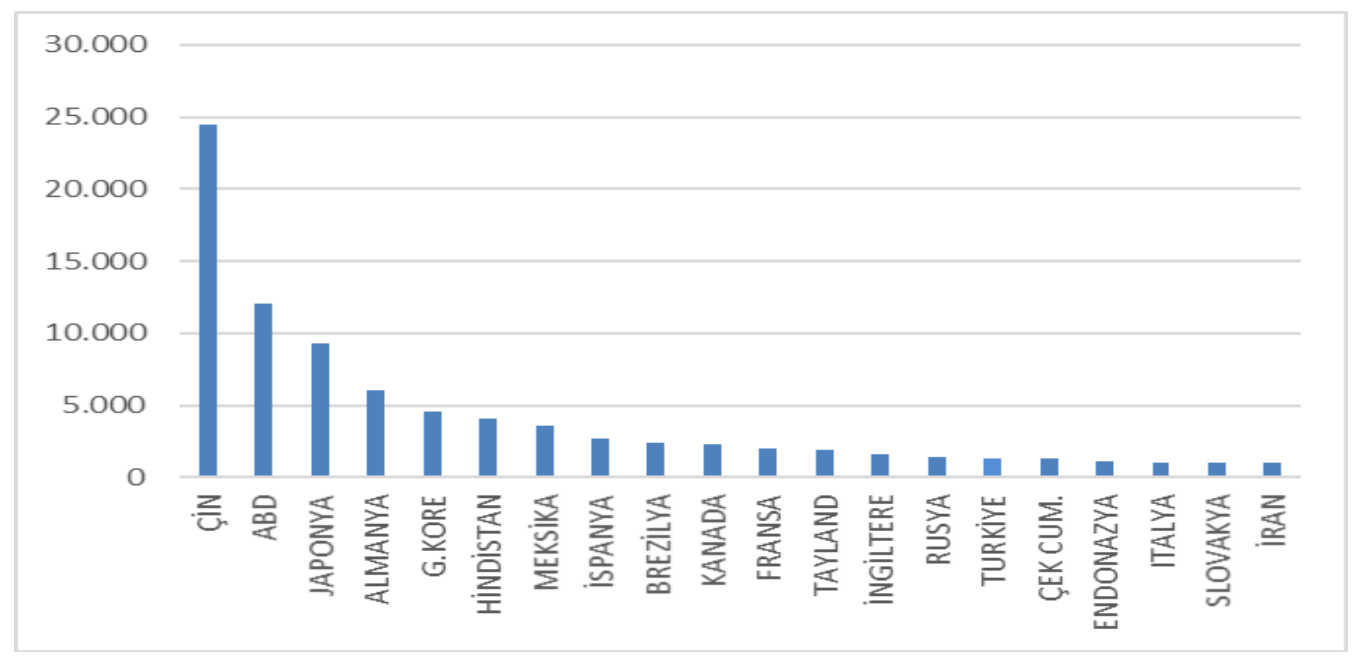

Grafik 1. 2015 Yılı Ülkeler Bazında Motorlu Araç Üretimi (X1.000)

Kaynak: Otomotiv Sanayii Derneği

Grafik 1'e göre 2015 yılında motorlu araç üretimi sıralamasında 24 milyon adet düzeyinde üretim ile ilk sırada Çin Halk Cumhuriyeti yer almıştır. Dünya üretimin yüzde 27'sini gerçekleştiren Çin Halk Cumhuriyeti'nin motorlu araç üretimi yıllara göre artmaktadır. İkinci sırada yer alan Amerika Birleşik Devletleri'nin motorlu üretimi ise 12 milyon adet düzeyine ulaşmıştır. Türkiye ise dünya motorlu araç üretiminde 1,3 milyon adet düzeyi ile 15. sırada yer almaktadır (Otomotiv Sanayii Derneği, Otomotiv Sanayii 2015 Yılı Küresel Değerlendirme Raporu, 2016: 8-9).

\section{LİTERATÜR İNCELEMESI}

Yurdakul ve İç (2003), Türkiye'de otomotiv sektöründe faaliyet gösteren ve hisseleri BİST'te işlem gören 5 otomotiv şirketine ait finansal oranlardan hareketle 1998-2001 dönemi için; TOPSIS yöntemini uygulamış, firma performansının hisse senetleri fiyatlarına göre benzer bir tutarlılık gösterdiğini tespit etmişlerdir.

Akkaya (2004) TOPSIS yöntemini kullanarak, finansal rasyolar yardımıyla bir havayolu firmasının performansını incelemiştir. Üretim, pazarlama ve faaliyet olmak üzere üç başlık oluşturarak bu başlıklar kapsamında da 63 rasyo belirlemiştir. Ayrıca gri ilişki analizi ve TOPSIS yöntemleri ile bu rasyolar her bir grubu temsil etmek üzere 
13 rasyoya indirgenmiştir. İlgili rasyolar yardımıyla yöntem uygulanmış ve havayolu firmasının ulusal rekabette önemli bir konumda olduğu sonucuna varmıştır.

Mahmoodzadeh, Shahrabi, Pariazar ve Zaeri (2007), farklı projelerin değerlendirilmesinde AHP ve TOPSIS yöntemlerini birlikte kullanarak, alternatif projeler değerlendirilmesinde belirlenen finansal oranlar yardımıyla en iyi projeyi bulmaya çalışmışlardır.

Eleren ve Karagül (2008), Türkiye ekonomisinin 1986-2006 dönemindeki performans seviyesini TOPSIS yöntemiyle araştırmışlardır. Belirledikleri kriterler doğrultusunda Türkiye ekonomisinin ilgili yıllardaki başarı durumunun değişkenlik gösterdiğini, bu değişkenliğe en büyük etkinin ise dış açıktan kaynaklandığını öne sürmüşlerdir.

Chang, Lin, Lin ve Chiang (2010) yatırım fonlarının değerlendirilmesinde TOPSIS yöntemini kullanmışlardır. Tayvan'da 82 yatırım fonunun 32 aylık verisinden yararlanarak belirlenen kriterler doğrultusunda kullanılan TOPSIS yönteminin, yatırım fonlarının performans değerlendirilmesinde olumlu verilerin elde edildiği sonucuna varmışlardır.

Yükçü ve Atağan (2010) çalışmalarında belirledikleri çeşitli finansal performans ölçütlerine göre seçmiş oldukları otellerin performanslarını TOPSIS yöntemi aracılığıyla tek bir puana indirgenerek değerlendirmişlerdir. Sonuç olarak farklı illerdeki otellerinin performansları karşılaştırılmalı olarak yorumlanabilmesi TOPSIS yönteminin farklı değerlendirme kriterlerini ortak çerçevede analiz edebilme olanağı sağladığı ve objektif bir değerleme imkanı sunduğunu tespit etmişlerdir.

Demireli (2010), ise ülke çapında yaygın olarak faaliyet gösteren kamu bankalarının performanslarını TOPSIS yöntemiyle analiz ederek sermayesi kamuya ait bankaların ulusal ve küresel finansal krizlerinden etkilendiğini, performans puanlarının yurtdışı verilere bağlı olarak oynaklık gösterdiğini ve sektörde kayda değer bir gelişmenin ortaya çıkmadığı bulgusuna ulaşmıştır.

Dumanoğlu ve Ergül (2010) çalışmalarında BİST'te faaliyet gösteren 11 teknoloji firmasının finansal tablolarından hareketle, 2006-2009 yılları arasında yer alan dört dönem için TOPSIS yöntemini kullanarak finansal performans değerlemesi karşılaştırmalı olarak incelemişlerdir. Sonuç olarak, teknoloji firmalarının finansal performanslarına ilişkin bulguların temel analiz sonuçlarıyla paralel olması, TOPSIS yönteminin kullanılabilir bir yöntem olduğu kanısına varmışlardır.

Dumanoğlu (2010), BİST'te işlem gören 15 çimento firmasının finansal tabloları aracılığıyla finansal performanslarını TOPSIS yöntemi ile incelemiştir. İlk olarak finansal oranlar hesaplanmış ve sonrasında ise TOPSIS yöntemi ile genel şirket performansını gösteren tek bir puan elde edilmiştir. Çalışmasında 2004-2009 döneminde yer alan 6 dönem için performans değerlemesi yaparak elde ettiği bulguları karşılaştırılmış bazı şirketlerin finansal performans sıralamasını istikrarlı bir şekilde koruduğu, bazılarının ise sıralamasının değişkenlik gösterdiğini tespit etmiştir. 
Akyüz, Bozdoğan ve Hantekin (2011) BİST'te işlem gören Seramik sektöründeki bir anonim şirketin, TOPSIS yöntemi yardımıyla 1999-2008 dönemini kapsayan verilerinden hareketle, 19 adet oran kullanılarak finansal performans değerlendirilmesi yapmışlardır. Bu yöntemi ile yıllar itibariyle elde edilen sonuçların doğru yorumlanabilmesi için sektör ortalamasının ve rakip firmaların finansal performans sonuçlarıyla karşılaştırılması gerektiğini düşünmüşlerdir.

Özgüven (2011), perakendecilik sektöründeki bazı hipermarketlerin (Migros, Carrefour ve Kipa) Ekonomist dergisinin 2009 yılı araştırmasına göre sıralamada ilk 10 'da bulunan şubelerini TOPSIS yöntemiyle yapmış olduğu analizde, söz konusu firmaların performanslarını daha yukarıya taşıyabilmeleri için, mevcut mağaza sayısını fazlalaştırmaları gerektiği, hakla ilişkiler faaliyetlerine verilen önemin artırılması gerektiği ve ürün çeşitlendirme stratejisi uygulamaları gerektiği sonucuna ulaşılmıştır.

Ömürbek ve Kınay (2013) BİST ve Frankfurt Menkul Kıymetler Borsası'nda işlem gören iki havayolu şirketinin 2012 yllındaki performans analizinde, finansal tablolarından yararlanarak belirledikleri finansal kriterleri TOPSIS yöntemi kullanılarak incelenmiş olup BİST'te işlem gören şirketin daha başarılı olduğunu tespit etmişlerdir.

Acar ve Güner (2014) ise bir konfeksiyon işletmesinde anahtar müşteriye ulaşabilmek için TOPSIS yöntemini kullanarak 5 adet kriter belirlemiştir. TOPSIS çalışmasında 4 alternatif müşteri düşünülerek yapılan uygulamada firma için en uygun müşteri bulunmaya çalışılmıştır.

Akbulut ve Rençber (2015) çalışmalrında BIST'te işlem gören İmalat sektöründeki 32 işletmenin 2010-2012 yılları arasındaki finansal performansları ile pazar değeri/defter değeri oranları karşılaştırılmıştır. 10 adet değişken ve borsa performansı için pazar değeri/defteri oranı değerlendirme kriteri olarak belirlenerek TOPSIS yöntemi aracılığı ile performans değerlemesi yapılmıştır.

Kayıhan (2017) çalışmasında BİST'te faaliyet gösteren taş ve toprağa dayalı sanayi sektörü işletmelerin 2012-2015 dönemini mali performanslarını TOPSIS yöntemi ile incelemiştir. 28 adet işletmenin, belirlenen 8 adet kriter doğrultusunda herbir yıl için karşılaştırılmalı değerlendirilmiş ve sonuç olarak yapılan çalışma diğer sektörlerdeki işletmeler için uygulanabilir ve işletmlerin finansal performans açısından değerlendirilmesinde yol gösterebilecği kanısına varmıştır.

Gümüş, Ercan, Tokyüz ve Çakmak (2017), BİST'te işlem görmekte olan ve çimento sektöründe faaliyet gösteren şirketlerin finansal tablolarından yola çıkarak, bu şirketlerin finansal performansını TOPSIS yöntemi ile incelemişlerdir. Yapılan uygulama ile elde edile sonuçların, geleneksel oranlara ve nakit akım oranlarına göre şirketlerin finansal performanslarının farklılık gösterdiğni tespit etmişlerdir. 


\section{METODOLOJi}

\subsection{Veri Toplama ve Metodoloji}

Otomotiv sektörü Türkiye ekonomisi açısından özel bir önem arz etmektedir. Türkiye ekonomisinde otomotiv sektörü yıllar içinde sürekli büyüyerek önemli bir sektör kolu olmuştur. Küresel ölçekli otomotiv üreticilerinin ülkemize yapmış olduğu teknoloji yatırımları ile birlikte üretim kalitesi de artmıştır. Üretim, pazarlama, satış ve satış sonrası hizmetler ile tüketici taleplerini göz önünde tutan otomotiv sanayisi, gün geçtikçe ülke ekonomisinde önemli role sahip olmuştur.

$\mathrm{Bu}$ çalışmanın amacl; Borsa İstanbul'da hisse senetleri işlem gören otomotiv sektöründeki 7 şirketin 2010-2015 yılları arasındaki finansal performanslarının TOPSIS yöntemiyle değerlendirilmesidir. Çalışma kapsamında ilgili dönemlerde Türkiye'de faaliyetlerini sürdüren Anadolu Isuzu Otomotiv Sanayi ve Ticaret A.Ş, Doğuş Otomotiv Servis ve Ticaret A.Ş, Ford Otomotiv Sanayi A.Ş, Karsan Otomotiv Sanayi ve Ticaret A.Ş, Otokar Otomotiv ve Savunma Sanayi A.Ş, Tofaş Türk Otomobil Fabrikası A.Ş ve Türk Traktör ve Ziraat Makineleri A.Ş analiz kapsamına alınmıştır. İlgili şirketlerin adaları ve BİST kodları Tablo 1'de yer almaktadır.

Tablo 1. İşletmelerin Adı ve BİST İşlem Kodu

\begin{tabular}{|l|l|}
\hline BİST İŞLEM KODU & İŞLETME ADI \\
\hline ASUZU & ANADOLU ISUZU OTOMOTIV SANAYİ VE TİCARET A.Ş \\
\hline DOAS & DOĞUŞ OTOMOTIV SERVİS VE TICARET A.Ş \\
\hline FROTO & FORD OTOMOTIV SANAYİ A.Ş \\
\hline KARSN & KARSAN OTOMOTIV SANAYİ VE TICARET A.Ş \\
\hline OTKAR & OTOKAR OTOMOTIV VE SAVUNMA SANAYİ A.Ş \\
\hline TOASO & TOFAŞ TÜRK OTOMOBILL FABRIKASI A.Ş \\
\hline TTRAK & TÜRK TRAKTÖR VE ZİRAAT MAKİNELERI A.Ş \\
\hline
\end{tabular}

Çalışmada, BİST'te hisse senetleri işlem gören otomotiv sektöründeki 7 şirketin 2010-2015 yıllarına ait bilanço ve gelir tablolarından elde edilen finansal veriler kullanılmıştır. Araştırmaya konu olan şirketlere ait veriler; KAP (Kamuyu Aydınlatma Platformu), BİST (Borsa İstanbul)'in internet sitelerinden ve şirketlerin faaliyet raporlarından elde edilmiştir. TOPSIS yönteminde performans değerlemesi yapılabilmesi için mali tablolardan yararlanarak belirli kriterlerin (finansal oranlar) seçilmesi gerekmektedir.

Seçilen finansal oranlar; Cari Oran, Toplam Borç/Toplam Varlık Oranı, Öz Sermaye/Toplam Varlık Oranı, Kısa Vadeli Yabancı Kaynaklar/Toplam Borç, Stok Devir Hızı, Net Kar/Öz Sermaye Oranı, Net Kar/Toplam Varlık Oranı, Brüt Satış Karı/Net Satışlar Oranı, Faaliyet Karı Oranı ve Çalışan Kişi Başına Net Satışlardır. Seçilen 10 adet finansal oranın TOPSIS yönteminde tek puana çevrilerek değerlendirme yapılabilmesi için bu oranlara belirli ağırlıklar verilmiştir. Bu çalışmada belirlenen finansal oranlar ve ağırlık değerleri tablo 2 ' de yer almaktadır. 
Tablo 2. Analizde Kullanılan Finansal Oranlar ve Kullanılan Semboller

\begin{tabular}{|l|c|c|}
\hline Kullanılan Oranlar & Sembolü & Ağırlık Değeri $\left(\mathbf{w}_{\mathbf{i}}\right)$ \\
\hline Cari Oran & $(\mathrm{CO})$ & 0,10 \\
\hline Toplam Borç/Toplam Varlık Oranı & $(\mathrm{TB} / \mathrm{TV})$ & 0,10 \\
\hline Öz Sermaye/Toplam Varlık Oranı & $($ ÖS/TV) & 0,10 \\
\hline Kısa Vadeli Yabancı Kaynaklar/Toplam Borç Oranı & $(\mathrm{KVYK/TB})$ & 0,10 \\
\hline Stok Devir Hızı & $(\mathrm{SDH})$ & 0,10 \\
\hline Net Kar/Öz Sermaye Oranı & (NK/ÖS) & 0,10 \\
\hline Net Kar/Toplam Varlık Oranı & (NK/TV) & 0,10 \\
\hline Brüt Satış Karı/Net Satışlar Oranı & (BSK/NS) & 0,10 \\
\hline Faaliyet Karı/Net Satışlar Oranı & (FK/NS) & 0,10 \\
\hline Çalışan Kişi Başına Net Satışlar & (ÇKBNS) & 0,10 \\
\hline
\end{tabular}

\subsection{TOPSIS Yöntemi}

Çok kriterli karar verme süreçleri, karmaşık karar problemlerinin bilimsel ve analitik bir çerçevede ele alınarak karar vericiye çözüme ulaşmasında yardımcı olmaya çalışan prosedürler bütünü olarak ortaya çıkmıştır. Bu açıdan son yıllarda kullanılan çok kriterli karar verme yöntemleriyle, birbirleriyle çelişebilen kriterlerin basit düzeyde karar almaya yardımcı olmalarıyla geniş kullanım alanına sahip olmuşlardır (Saldanlı ve Sirma, 2014: 186).

TOPSIS (Technique For Order Prefence by Similarity to Ideal Solution) tekniği 1981 yılında Hwang ve Yoon K.'nın çalışmalarıyla geliştirilen yöntem çok kriterli karar verme yöntemlerinden en çok kullanılanlarındandır. Bu teknik şirketlerin finansal performanslarının değerlendirilmesinde anlamlı ve anlaşılır sonuçlar verir. TOPSIS yöntemi pozitif ideal ve negatif ideal çözüm sarmalında şirket için optimal çözümün; pozitif ideal çözüme en yakın, negatif ideal çözüme en uzak noktasında oluşacağ 1 algısına dayanan bir varsayımdan hareketle geliştirilmiş bir yöntemdir. Günümüzde TOPSIS yöntemi, finansal oranlar kullanarak elde edilen sonuçlar doğrultusunda şirketlerin değerlendirilmesinde ve karşılaştırılmasında yardımcı olur. Aşağıda TOPSIS yönteminin aşamaları açıklanmıştır (Dumanoğlu ve Ergül, 2010:105-107; Korkmaz ve Uygurtürk, 2012: 103-105).

\subsubsection{TOPSIS Yönteminin Aşamaları}

\section{1) Aşama: Karar Matrisinin Oluşturulması}

Karar matrisi karar verici tarafından oluşturulur. Karar verici tarafından oluşturulan karar matrisinde; satırlar üstünlüklerine göre sıralanmak istenen alternatifler, sütunlar ise karar verici tarafından belirlenen ve karar vermede kullanılmak istenen ölçütler (kriterler) yer almaktadır. Oluşturulan A matrisi karar verici için başlangıç matrisidir ve aşağıda gösterildiği gibidir: 


$$
A_{i j}=\left[\begin{array}{cccc}
a_{11} & a_{12} & \ldots & a_{1 n} \\
a_{21} & a_{22} & \ldots & a_{2 n} \\
\cdot & & & \cdot \\
\cdot & & & \cdot \\
\cdot & & & \cdot \\
a_{m 1} & a_{m 2} & \ldots & a_{m n}
\end{array}\right]
$$

Karar verici tarafından oluşturulan A matrisindeki $A_{i j}$ simgesi matristeki sıralanmak istenen her bir $i$ alternatifinin $j$ ölçütüne göre gerçek değerini göstermektedir ve satırlar seçenekleri sütunlar ise kriterleri ifade eder. A matrisinde $m$ karar noktası (alternatif) sayısını, n değerlendirme kriteri sayısını vermektedir.

\section{2) Aşama: Normalize Edilmiş Karar Matrisini (R) Oluşturulması}

Karar vericinin oluşturmuş olduğu başlangıç matrisinin 2. aşamasında normalizasyon işlemi yapılır. Bu aşamada farklı teknikler bulunmaktadır. Vektör normalizasyonu en çok kullanılan yöntemlerden birisidir. Normalizasyon işlemi yapılırken oluşturulan karar matrisinin elemanlarından faydalanılarak aşağıdaki formül kullanılır. Alternatifin sütundaki mevcut değerinin, ilgili sütundaki tüm değerlerin kareleri toplamının kareköküne bölünmesiyle bulunur.

$$
r_{i j}=\frac{a_{i j}}{\sqrt{\sum_{k=1}^{m} a_{k j}^{2}}}
$$

R Matrisi aşağıdaki gibi elde edilir.

$$
R_{i j}=\left[\begin{array}{cccc}
r_{11} & r_{12} & \ldots & r_{1 n} \\
r_{21} & r_{22} & \ldots & r_{2 n} \\
\cdot & & & \cdot \\
\cdot & & & \cdot \\
\cdot & & & \cdot \\
r_{m 1} & r_{m 2} & \ldots & r_{m n}
\end{array}\right]
$$

\section{3) Aşama: Ağırlıklı Standart Karar Matrisinin (V) Oluşturulması}

Normalize edilmiş karar matrisi oluşturulduktan sonra her bir değerlendirme kriterine ilişkin ağırlık değerleri $\left(\mathrm{w}_{\mathrm{i}}\right)$ belirlenir. Belirlenen ağırlık değerleri $\left(\mathrm{w}_{\mathrm{i}}\right)$ normalize edilmiş olan $\mathrm{R}$ matrisinin her bir sütunundaki elemanlar ilgili wi değeri ile çarpılır ve Ağırlıklı Standart Karar Matrisi (V) matrisi oluşturulur. Oluşturulan V matrisi aşağıda yer almaktadır. 


$$
V_{i j}=\left[\begin{array}{cccc}
w_{1} r_{11} & w_{2} r_{12} & \ldots & w_{n} r_{1 n} \\
w_{1} r_{21} & w_{2} r_{22} & \ldots & w_{n} r_{2 n} \\
\cdot & & & \cdot \\
\cdot & & & \cdot \\
\cdot & & & \cdot \\
w_{1} r_{m 1} & w_{2} r_{m 2} & \ldots & w_{n} r_{m n}
\end{array}\right]
$$

Sütunlardaki her bir değerlendirme kriterlerine ilişkin ağırlıklar $\mathrm{W}_{1}, \mathrm{~W}_{2}, \mathrm{~W}_{3} \ldots \ldots \ldots, \mathrm{W}_{\mathrm{n}}$ şeklinde yer alır ve $\mathrm{R}$ matrisinin sütunlarındaki değerler ilgili değerlendirme kriteri ağırlık değerleri ile çarpılarak $\mathrm{V}$ matrisinin sütunları hesaplanmaktadir.

Yöntemin bu aşamasında dışarıdan müdahalenin olduğu tek yerdir. Çünkü karar verici tarafından ağırlık değerleri $\left(\mathrm{w}_{\mathrm{i}}\right)$ belirlenir. Bu kısımda farklı yöntemler bulunmakla beraber ağırlık değerlerinin belirlenmesi araştırmacının inisiyatifine bağlıdır. Bu çalışmada ağırlık katsayılarını eşit olarak belirlenmiştir.

\section{4) Aşama: İdeal $\mathrm{A}^{+}$ve Negatif İdeal A- Çözümlerin Oluşturulması}

TOPSIS yöntemi, her bir değerlendirme kriterinin monoton artan veya azalan bir eğilime sahip olduğunu varsaymaktadır. TOPSIS yönteminin bu aşamasında oluşturulan ağırlıklı standart karar matrisine ait değerlendirme kriterlerinin yani sütun değerlerinin en büyükleri ve en küçükleri seçilir. İdeal çözüm setinin bulunması aşağıda gösterilmiştir. Bu aşamada ağırlıklandırılmış matriste her bir kolonda yer alan maksimumu ve minimum değerler tespit edilmektedir.

$$
\begin{aligned}
& A^{+}=\left\{\left(\max v_{i j} \mid j \in J\right),\left(\min v_{i j} \mid j \in J^{\prime}\right\}\right. \\
& A^{-}=\left\{\left(\min v_{i j} \mid j \in J\right),\left(\max v_{i j} \mid j \in J^{\prime}\right\}\right.
\end{aligned}
$$

Her iki formülde de J maksimum J' ise minimum değeri göstermektedir.

$$
\begin{aligned}
& \mathrm{A}^{+}=\left(\mathrm{V}^{+}, \mathrm{V}_{2}{ }^{+}, \mathrm{V}^{+}, \ldots . \mathrm{Vn}^{+}\right) \text {(maksimum değerler) } \\
& \mathrm{A}^{-}=\left(\mathrm{V}^{-}, \mathrm{V}_{2}{ }^{-}, \mathrm{V}^{2}, \ldots . . . . \mathrm{Vn}^{-}\right) \text {(minimum değerler) }
\end{aligned}
$$

\section{5) Aşama: Alternatiflerin Arasındaki Mesafe Ölçülerinin Hesaplanması}

Belirlenen maksimum ve minimum değerlerin ardından yöntemin 5 . aşamasında maksimum ve minimum ideal noktalara olan uzaklık değerleri aşağıdaki formüller yardımıyla hesaplanmaktadır (Mahmoodzadeh vd., 2007: 337).

Bu aşamada her bir alternatifin pozitif ideal çözümden $\left(\mathrm{S}_{\mathrm{i}}^{*}\right)$ ve negatif ideal $\left(\mathrm{S}_{\mathrm{i}}{ }^{-}\right)$ çözümden mesafesi hesaplanır. 


$$
\begin{aligned}
& S_{i}^{*}=\sqrt{\sum_{j=1}^{n}\left(v_{i j}-v_{j}^{*}\right)^{2}} \quad \mathrm{i}=1,2,3, \ldots, \mathrm{m} \\
& S_{i}^{-}=\sqrt{\sum_{j=1}^{n}\left(v_{i j}-v_{j}^{-}\right)^{2}} \quad \mathrm{i}=1,2,3, \ldots, \mathrm{m}
\end{aligned}
$$

\section{6) Aşama: İdeal Çözüme Göreli Yakınlığın Hesaplanması}

Her bir alternatifin ideal çözüme göreli yakınlığının $\left(\mathrm{C}_{i}^{*}\right)$ hesaplanmasında ideal ve negatif ideal ayırım ölçülerinden yararlanılmaktadır. Burada kullanılan ölçüt, negatif ideal ayırım ölçüsünün toplam ayırım ölçüsü içindeki payıdır. İdeal çözüme göreli yakınlık değerinin hesaplanması aşağıdaki formülde gösterilmiştir.

$$
C_{i}^{*}=\frac{S_{i}^{-}}{S_{i}^{-}+S_{i}^{*}} \quad \mathrm{i}=1,2,3,4, \ldots \ldots, \mathrm{m}
$$

Burada $\mathrm{C}_{\mathrm{i}}^{*}$ değeri $0<\mathrm{C}_{\mathrm{i}}^{*}<1$ aralığında değer alır ve $\mathrm{C}_{\mathrm{i}}^{*}=1$ ilgili karar noktasının ideal çözüme, $C_{i}^{*}=0$ ilgili karar noktasının negatif ideal çözüme mutlak yakınlığını göstermektedir. Çalışmanın bu bölümünde araştırma kapsamında 2010-2015 yılları dahil olmak üzere 6 yıl incelenmiştir. Çalışmaya 2010 yılı örnek teşkil etmesi amacıyla değerlendirme kriterlerinin ağırlık değerleri eşit kabul edilerek yapılan TOPSIS uygulaması incelenmiştir. İlerleyen kısımlarda ilgili yıllar Tablo üzerinden özetlenmektedir.

\subsection{Analitik Bulgular}

\section{1) Aşama: Karar Matrisini Oluşturma}

TOPSIS yönteminin birinci aşması karar matrisinin oluşturulmasıdır. Karar matrisinin satırlarında üstünlükleri sıralanmak istenen karar noktaları, sütunlarda ise karar vermede kullanılacak değerlendirme faktörleri yer almaktadır. Çalışmada 7 karar noktası (şirketler) ve 10 değerlendirme faktörü (finansal oranlar) bulunmaktadır. İlk olarak TOPSIS yöntemi için (7x10) boyutlu karar matrisi oluşturulmuştur.

Tablo 3. 2010 Yilı Karar Matrisi

\begin{tabular}{|l|c|c|c|c|c|c|c|c|c|c|}
\hline 2010 YIII & CO & TB/TV & ÖS/TV & KVYKITB & SDH & NK/ÖS & NKITV & BSKINS & FK/NS & ÇKBNS \\
\hline ASUZU & 1,52 & 0,51 & 0,49 & 0,95 & 2,33 & $-0,02$ & $-0,01$ & 0,12 & $-0,004$ & 693 \\
\hline DOAS & 1,06 & 0,51 & 0,49 & 0,87 & 8,45 & 0,2 & 0,1 & 0,14 & 0,05 & 1.959 \\
\hline FROTO & 1,97 & 0,47 & 0,53 & 0,71 & 17,65 & 0,28 & 0,15 & 0,12 & 0,08 & 909 \\
\hline KARSN & 0,64 & 0,73 & 0,27 & 0,78 & 8,22 & $-0,37$ & $-0,09$ & 0,006 & $-0,05$ & 550 \\
\hline OTKAR & 1,18 & 0,73 & 0,27 & 0,79 & 3,7 & 0,12 & 0,03 & 0,17 & 0,05 & 394 \\
\hline TOASO & 1,35 & 0,67 & 0,33 & 0,57 & 18,74 & 0,22 & 0,07 & 0,11 & 0,06 & 930 \\
\hline ITRAK & 2,06 & 0,48 & 0,52 & 0,86 & 6,47 & 0,38 & 0,2 & 0,26 & 0,18 & 656 \\
\hline
\end{tabular}




\section{2) Aşama: Normalize Edilmiş Karar Matrisinin Oluşturulması}

Tüm yıllara ait normalize edilmiş karar matrisleri, karar matrisinin sütunlarındaki her bir değerin (kriterler) ilgili sütundaki değerlerin kareleri toplamının kareköküne bölünüp tek paydaya indirgenmesi suretiyle bulunur. 2010 yılına ait oluşturulan matris aşağıdaki tabloda gösterilmiştir.

Tablo 4. 2010 Yılı Nomalize Edilmiş Karar Matrisi

\begin{tabular}{|l|c|c|c|c|c|c|c|c|c|c|}
\hline 2010 YIII & CO & TB/TV & OS/TV & KVYKITB & SDH & NKIÖS & NKITV & BSKINS & FKINS & ÇKBNS \\
\hline ASUZU & 0,39 & 0,323 & 0,432 & 0,45 & 0,079 & $-0,029$ & $-0,034$ & 0,303 & $-0,018$ & 0,264 \\
\hline DOAS & 0,272 & 0,323 & 0,432 & 0,412 & 0,288 & 0,294 & 0,34 & 0,353 & 0,224 & 0,746 \\
\hline FROTO & 0,506 & 0,298 & 0,467 & 0,336 & 0,601 & 0,412 & 0,51 & 0,303 & 0,358 & 0,346 \\
\hline KARSN & 0,164 & 0,463 & 0,238 & 0,369 & 0,28 & $-0,544$ & $-0,306$ & 0,015 & $-0,224$ & 0,209 \\
\hline OTKAR & 0,303 & 0,463 & 0,238 & 0,374 & 0,126 & 0,176 & 0,102 & 0,429 & 0,224 & 0,15 \\
\hline TOASO & 0,346 & 0,425 & 0,291 & 0,27 & 0,638 & 0,323 & 0,238 & 0,278 & 0,269 & 0,354 \\
\hline TTRAK & 0,529 & 0,304 & 0,459 & 0,407 & 0,22 & 0,559 & 0,68 & 0,656 & 0,806 & 0,25 \\
\hline
\end{tabular}

\section{3) Aşama: Ağırlıklı Standart Karar Matrisinin Oluşsturulması}

Üçüncü aşamada değerlendirme faktörlerine ilişkin ağırlık dereceleri $\left(\mathrm{w}_{\mathrm{j}}\right)$ belirlenerek, bir önceki adımda hesaplanan normalize edilmiş değerler, $\left(w_{j}\right)$ değerleri ile çarpılarak ağırlıklandırılmış normalize edilmiş değerler bulunmaktadır. Ağırlık hesaplaması TOPSIS yönteminde dışarıdan müdahalenin olduğu tek yerdir.

Tablo 5'te değerlendirme faktörü olan finansal oranların eşit öneme sahip olduğu varsayılarak, ağırlık kat sayıları CO $(0,10)$, TB/TV $(0,10)$, ÖS/TV $(0,10)$, KVYK/TB $(0,10)$, SDH $(0,10)$, NK/ÖS $(0,10)$, NK/TV $(0,10), \operatorname{BSK} / \mathrm{NS}(0,10)$, FK/NS $(0,10)$ ve ÇKBNS $(0,10)$ olarak belirlenmiştir.

\section{4) Aşama: Maksimum/Minimum Değerlerin Belirlenmesi}

Dördüncü aşamada ise sonuçlara göre oluşturulan Ağırlıklı Standart Karar Matrisleri ayrıca ideal $\mathrm{A}^{+}$ve negatif ideal $\mathrm{A}^{-}$çözüm kümeleri oluşturulmaktadır. $\mathrm{A}^{+}$seti için V matrisinin her bir sütunundaki en büyük değer, $\mathrm{A}^{-}$seti için V matrisinin her bir sütunundaki en küçük değer seçilmiş olup tablo 5'te yer almaktadır. 
Tablo 5. 2010 Yılı Ağırlıklı Standart Karar Matrisinin Oluşturulması ve Maksimum/Minimum Değerlerin Belirlenmesi

\begin{tabular}{|l|c|c|c|c|c|c|c|c|c|c|}
\hline 2010 YIII & CO & TB/TV & ÖS/TV & KVYKITB & SDH & NKIÖS & NKITV & BSKINS & FKINS & ÇKBNS \\
\hline ASUZU & 0,039 & 0,032 & 0,043 & 0,045 & 0,008 & $-0,003$ & $-0,003$ & 0,03 & $-0,002$ & 0,026 \\
\hline DOAS & 0,027 & 0,032 & 0,043 & 0,041 & 0,029 & 0,029 & 0,034 & 0,035 & 0,022 & 0,075 \\
\hline FROTO & 0,051 & 0,03 & 0,047 & 0,034 & 0,06 & 0,041 & 0,051 & 0,03 & 0,036 & 0,035 \\
\hline KARSN & 0,016 & 0,046 & 0,024 & 0,037 & 0,028 & $-0,054$ & $-0,031$ & 0,002 & $-0,022$ & 0,021 \\
\hline OTKAR & 0,03 & 0,046 & 0,024 & 0,037 & 0,013 & 0,018 & 0,01 & 0,043 & 0,022 & 0,015 \\
\hline TOASO & 0,035 & 0,042 & 0,029 & 0,027 & 0,064 & 0,032 & 0,024 & 0,028 & 0,027 & 0,035 \\
\hline TTRAK & 0,053 & 0,03 & 0,046 & 0,041 & 0,022 & 0,056 & 0,068 & 0,066 & 0,081 & 0,025 \\
\hline max & 0,053 & 0,046 & 0,047 & 0,045 & 0,064 & 0,056 & 0,068 & 0,066 & 0,081 & 0,075 \\
\hline min & 0,016 & 0,03 & 0,024 & 0,027 & 0,008 & $-0,054$ & $-0,031$ & 0,002 & $-0,022$ & 0,015 \\
\hline
\end{tabular}

5) Aşama: Pozitif İdeal Çözüm $\left(\mathrm{S}_{\mathrm{i}}^{*}\right)$ ve Negatif İdeal $\left(\mathrm{S}_{\mathrm{i}}{ }^{-}\right)$Çözüm

Her alternatifin pozitif ideal çözümden olan mesafesi $\left(\mathrm{Si}^{*}\right)$ ve negatif ideal çözümden olan mesafesi ( $\left.\mathrm{Si}_{\mathrm{i}}\right)^{-}$hesaplanmış olup aşağıdaki tabloda gösterilmiştir. Tablo $6^{\prime}$ da eşit öneme sahip ağırlık değerlerine ait $S_{i}^{*}$ ve $S_{i-}$ verileri yer almaktadır.

Tablo 6. 2010 Yılı Pozitif İdeal Çözüm $\left(\mathrm{Si}_{\mathrm{i}}^{*}\right)$ ve Negatif İdeal (Si $)$ Çözüm

\begin{tabular}{|l|c|c|}
\hline $\mathbf{2 0 1 0}$ Yilı $^{\prime}$ & $\mathbf{S}_{\mathrm{i}}{ }^{*}$ & $\mathbf{S}_{\mathrm{i}}{ }^{{ }^{\prime}}$ \\
\hline ASUZU & 0,15 & 0,077 \\
\hline DOAS & 0,091 & 0,138 \\
\hline FROTO & 0,076 & 0,158 \\
\hline KARSN & 0,207 & 0,028 \\
\hline OTKAR & 0,126 & 0,106 \\
\hline TOASO & 0,097 & 0,133 \\
\hline TTRAK & 0,067 & 0,197 \\
\hline
\end{tabular}

\section{6) Aşama: İdeal Çözüme Göreli Yakınlığın Hesaplanması}

Her bir karar noktasının ideal çözüme göreli yakınlı̆̆ı denkleme göre hesaplanmıştır. Eşit ve öneme sahip olarak yapılan TOPSIS değerlendirmesi sonucunda hesaplanan $\mathrm{Ci}^{*}$ değerleri sırasıyla tablo $7^{\prime}$ de gösterilmiştir. 
Tablo 7. 2010 Yılı İdeal Çözüme Göreli Yakınlık

\begin{tabular}{|l|c|c|}
\hline $\mathbf{2 0 1 0}$ Yılı & $\mathbf{c}_{\mathbf{i}}{ }^{*}$ & Sıralama \\
\hline ASUZU & 0,341 & 6 \\
\hline DOAS & 0,603 & 3 \\
\hline FROTO & 0,675 & 2 \\
\hline KARSN & 0,121 & 7 \\
\hline OTKAR & 0,455 & 5 \\
\hline TOASO & 0,579 & 4 \\
\hline TTRAK & 0,747 & 1 \\
\hline
\end{tabular}

Tablo 8. 2010-2015 Yılları Arasındaki Şirketlerin Cii Değerleri

\begin{tabular}{|l|c|c|c|c|c|c|c|c|c|c|c|c|}
\hline & $C_{i}^{*}$ & 2010 & $c_{i}^{*}$ & 2011 & $c_{i}^{*}$ & 2012 & $c_{i}^{*}$ & 2013 & $c_{i}^{*}$ & 2014 & $c_{i}^{*}$ & 2015 \\
\hline ASUZJ & 0,341 & 6 & 0,337 & 6 & 0,317 & 6 & 0,537 & 1 & 0,547 & 6 & 0,363 & 6 \\
\hline DOAS & 0,003 & 3 & 0,495 & 4 & 0,619 & 2 & 0,473 & 3 & 0,698 & 1 & 0,615 & 2 \\
\hline FROTO & 0,675 & 2 & 0,606 & 2 & 0,617 & 3 & 0,397 & 4 & 0,618 & 4 & 0,597 & 3 \\
\hline KARSN & 0,121 & 7 & 0,157 & 7 & 0,087 & 7 & 0,233 & 7 & 0,142 & 7 & 0,127 & 7 \\
\hline OTKAR & 0,455 & 5 & 0,446 & 5 & 0,538 & 5 & 0,352 & 6 & 0,587 & 5 & 0,493 & 5 \\
\hline TOASO & 0,579 & 4 & 0,499 & 3 & 0,568 & 4 & 0,361 & 5 & 0,645 & 3 & 0,572 & 4 \\
\hline TRAK & 0,447 & 1 & 0,696 & 1 & 0,7 & 1 & 0,528 & 2 & 0,668 & 2 & 0,619 & 1 \\
\hline
\end{tabular}

Çalışmada yapılan TOPSIS uygulaması sonucunda 2010-2015 yılları için elde edilen bulgular tablo 8'de özetlenmiştir. Tablo 8'i incelediğimizde Türk Traktör ve Ziraat Makineleri A.Ş, satışların yüksek olması, yabancı kaynak kullanımını dengede tutması ve gerekli olan yatırımlarını yapmasından dolayı yıllar itibariyle genel anlamda 2013 ve 2014 yılları hariç ilk sırada yer almaktadır. Anadolu Isuzu Otomotiv Sanayi ve Ticaret A.Ş’nin 2013 yılında ilk sırayı almasında satışların yüksek olması, bir önceki yıla göre toplam borçlarının azalması, önemli oranda hisse senedi satarak sermaye artırımına gitmesi ve gayrımenkul satışı yapmasının etkisi bulunmaktdır. 2014 yılında ise Doğuş Otomotiv Servis ve Ticaret A.Ş’nin bir önceki yıla göre satışlarının artması ve uzun vadeli yabancı kaynak kullanımının azalmasının yanında Türk Traktör ve Ziraat Makineleri A.Ş’nin yeni tesis kurmak için kullanmış oldukları banka kredileri ve tesis için gerekli olan makine-teçhizat alımının etkisi görülmektedir. Karsan Otomotiv Sanayi ve Ticaret A.Ş’nın son sırayı almasında yıllar içindeki yabancı kaynak kullanımının yüksek olması, Hyundai Motor Company ile yapılan anlaşma sonucunda gerekli olan yatırımlarını tahvil çıkararak ya da banka kredisi kullanarak yapması ve toplam borçlarının içinde kısa vadeli yabancı kaynak kullanım oranın yüksek olmasından kaynaklanmaktadır. Satış rakamları yüksek olsa da finansal maliyetler şirket karını olumsuz etkilemiştir. Otokar Otomotiv ve Savunma Sanayi A.Ş ve Anadolu Isuzu Otomotiv Sanayi ve Ticaret A.Ş yıllar itibariyle istikrarlı bir şekilde 
ilerlemeleri daha çok riskten kaçınarak hareket etmelerinden kaynaklanmaktadır. Ford Otomotiv Sanayi A.Ş, Tofaş Türk Otomobil Fabrikası A.Ş ve Doğuş Otomotiv Servis ve Ticaret A.Ş ise satışların, kullanılan yabancı kaynak oranın değişkenlik göstermesi ve yatırım yapma gerekliliği sıralamalarını yıllar itibariyle etkilemiştir.

\section{SONUÇ}

Şirketlerin piayasada varlı̆̆ını sürdürebilmesi, diğer şirketlerle rekabet edilebilmesine ve yaşanan değişimlere hızlı bir şekilde uyum sağlamasına bağlıdır. Bir şirketin finansl rasyolar yardımıyla finansal performansını ölçmesi ve değerlendirmesi şirketin piyasa değerinin berlirlenmesi ve karşılaştırma yaparak gerekli tedbirlerin alınma imkanı sağlamasından dolayı oldukça önemlidir.

Çalışmada otomotiv sektörünün önemi doğrultusunda ülkemizde faaliyet gösteren ve BİST'te hisse senetleri işlem gören 7 adet büyük ölçekli otomotiv şirketinin finansal yapıları 2010, 2011, 2012, 2013, 2014 ve 2015 yılları için değerlendirilmiş, belirlenen finansal oranlar doğrultusunda TOPSIS yöntemi uygulanmış ve elde edilen performans sonuçlarına göre kendi aralarında bir sıralama gerçekleştirilmiştir. Uygulanan TOPSIS yöntemi, incelenen şirketlerin finansal oranlarının matematiksel olarak tek bir puana dönüştürülerek elde edilen sonuçların analizini daha somut hale gelmesine yardımcı olmuştur.

Performans değerlelemsinde 10 adet kriter (rasyo) seçilmiş ve seçilen bu kriterler TOPSIS yönteminin aşamalarından biri olan ağırlıklar ile ağırlıklandırılmıştır. Karar vericinin etkin olduğu bu bölümde, değerlendirme kriterlerine verdiği ağırlıklar değişkenlik gösterebilir. Yurdakul ve İç (2003), Dumanoğlu (2010), Ömürbek ve Kınay (2013), Acar ve Güner (2014) değerlendirme kiterlerine vermiş oldukları ağırlık değerleri farklı iken Demireli (2010) ve bu çalışmada değerlendirme kriterlerine verilen ağırlık değerleri eşit kabul edilmiştir.

Yapılan çalışmada incelenen 7 şirketin 2010-2015 yıllan arasında her yıl için finansal performansları çerçevesinde oluşan sıralamadaki yerine göre, belirlenen grup içerisinde genel başarı durumu değerlendirilmiştir. Yapılan değerlendirme sonucuna göre bazı şirketlerin grup içindeki sıralamasını istikrarlı bir şekilde koruduğu ve bu istikrarın başta yöneticiler ve şirkete yatırım yapanlar için aranan bir unsur olmuştur. Elde edilen sonuçlar doğrultusunda ortakların şirkete olan kaynak yatırımlarını arttırdığı görülmektedir. Ayrıca şirketlerin bu başarıdan dolayı kaynaklarını yeni teknolojik yatırımlara yöneltmiştir. Bir grup şirketin ise sıralamadaki yeri değişkenlik göstermektedir. Bu şirketlerde satışların her yıl artmasına rağmen kullanılan yabancı kaynak oranının yüksek olması, diğer iç ve diş etkenlerden dolayı incelenen grup içindeki sıralamasını etkilemiştir.

Ayrıca yıllar içinde yaşanan ulusal ve uluslararası makro değişkenler, firmaların yeni anlaşmalar ya da yeni ürün geliştirme sonucunda üretim bandından değişikliğe gitmesi ve tüketicinin talepleri sonucunda satış miktarları gibi değişik faktörlerin de ideal çözümü olumlu ya da olumsuz etkileyeceği görülmüştür. Yine de 
şirketlerin başarı sıralamaları ve değişkenlikler şirketlerin temel analizleri ve ulaşılan piyasa verileriyle daha iyi anlaşılabilecektir.

Otomotiv sektöründe faaliyet gösteren şirketlerin üretimde amacı katma değer üretme ve kalite düzeyinin artırılmak iken şirket ölçütünde ise karlılığı yükseltmek ve yaşamının sürdürülebilirliğini sağlamaktır. $\mathrm{Bu}$ nedenle şirketler finansal performanslarını belirli zaman aralıklarında değerlendirmesi gerekmektedir.

\section{KAYNAKÇA}

Acar, E. ve Güner, M. (2014). Bir Konfeksiyon İşletmesinde Anahtar Müşterinin TOPSIS Çok Kriterli Karar Verme Metodu Kullanılarak Belirlenmesi. XUI. Uluslararası Tekstil Ve Hazır Giyim Sempozyumu, Nisan 2-5, İzmir.

Akbulut, R. ve Rençber, Ö.F. (2015). BİST'te İmalat Sektöründeki İşletmelerin Finansal Performansları Üzerine Bir Araştırma. Muhasebe ve Finansman Dergisi, 65, 118-136.

Akdoğan, N. ve Tenker, N. (1997). Finansal Tablolar ve Mali Analiz Teknikleri. 5. Baskı Lebib Yalkın Yayınları, Ankara.

Akgüç, Ö. (1995). Finansal Yönetim. 8. Baskı, Muhasebe Enstitüsü Yayını, İstanbul.

Akkaya, G. (2004). Finansal Rasyolar Yardımıyla Havayolu İşletmelerinin Performansının Değerlendirilmesi. Dokuz Eylül Üniversitesi İ.İ.B.F. Dergisi, 19(1): 15-29.

Akyüz, Y., Bozdoğan, T. ve Hantekin, E. (2011). TOPSIS Yöntemiyle Finansal Performansın Değerlendirilmesi ve Bir Uygulama. Afyon Kocatepe Üniversitesi İ.I.B.F. Dergisi, 13(1): 7392.

Chang, C., Lin, J., Lin, J. ve Chiang, M. (2010). Domestic Open-End Equity Mutual Fund Performance Evaluation Using Extended TOPSIS Method With Different Distance Approaches. Expert Systems with Applications, 37(6): 4642-4649.

Demireli, E. (2010). TOPSIS Çok Kriterli Karar Verme Sistemi: Türkiye'deki Kamu Bankaları Üzerine Bir Uygulama. Girişimcilik ve Kalkınma Dergisi, 5(1): 101-112.

Dumanoğlu, S. (2010). İMKB'de İşlem Gören Çimento Şirketlerinin Mali Performansının TOPSIS Yöntemiyle Değerlendirilmesi. Marmara Üniversitesi İ.I.B.F. Dergisi, 29(2): 223339.

Dumanoğlu, S. ve Ergül, N. (2010). İMKB'de İşlem Gören Teknoloji Şirketlerinin Mali Performans Ölçümü. Muhasebe ve Finansman Dergisi, 48: 101-111.

Eleren, A. ve Karagül, M. (2008). 1986-2006 Türkiye Ekonomisinin Performans Değerlendirilmesi. Yönetim ve Ekonomi Dergisi, 15(1): 1-14.

Gümüş, U. T., Ercan, A. S., Tokyüz, E. ve Çakmak, D. (2017). Evaluation of the Ratio Analysis Results of the Cement Companies at BIST-100 by Topsis Method. Journal of Current Researches on Social Sciences, 7 (2): 65-76.

Hwang, C. ve Kwangsun, Y. (1981). Multiple Attribute Decision Making Methods and Applications. Springer Verlag, New York.

Haftacı, V. (2009). Maliyet Muhasebesi. 1. Baskı, Umuttepe Yayınevi, Kocaeli.

Karapınar, A. ve Zaif, F. (2013). Finansal Analiz. 3. Baskı, Gazi Kitapevi, Ankara. 
Karbuz, F., Silahçı, A., ve Çalışkan, E. (2008). Otomotiv Sektör Raporu. İstanbul Ticaret Odası Ekonomi ve Sosyal Araştırmalar Şubesi, http://www.ito.org.tr/Dokuman/Sektor/169.pdf.

Korkmaz, T. ve Uygurtürk, H. (2012). Finansal Performansın TOPSIS Çok Kriterli Karar Verme Yöntemi ile Belirlenmesi: Ana Metal Sanayi İşletmeleri Üzerine Bir Uygulama. Eskişehir Osmangazi Üniversitesi İ̈BF Dergisi, 7(2): 95-115.

Kayıhan, B. (2017). Mali Performans Analizi: Bist Taş Ve Toprağa Dayalı Sanayi Sektörü İşletmelerinde Bir Uygulama. The Journal of Academic Social Science, 46: 453-469.

Mahmoodzadeh S., J. Shahrabı, M. Parıazar ve M. S. Zaerı (2007). Project Selection by Using Fuzzy AHP and TOPSIS Technique. World Academy of Science, Engineering and Technology, 30: 333-338.

Otomotiv Sanayii Derneği, (2016) Otomotiv Sanayii 2015 Yılı Değerlendirme Raporu. http://www.osd.org.tr/sites/1/upload/files/2015_Kuresel_Degerlendirme_Raporu139.pdf.

Ömürbek, V. ve Kınay, B. (2013). Havayolu Taşımacılığı Sektöründe TOPSIS Yöntemiyle Finansal Performans Değerlendirmesi. Süleyman Demirel Üniversitesi İktisadi ve İdari Bilimler Fakültesi Dergisi, 18(3): 343-36.

Özgüven, N. (2011). Kriz Döneminde Küresel Perakendeci Aktörlerin Performanslarının TOPSIS Yöntemi ile Değerlendirilmesi. Atatürk Üniversitesi İktisadi ve İdari Bilimler Dergisi, 25(2): 151-162.

Saldanlı, A. ve Sırma, İ. (2014). TOPSIS Yöntemiyle Finansal Performans Göstergesi Olarak Kullanılabilirliği. Marmara Üniversitesi Öneri Dergisi, 11(41): 185-202.

T.C. Bilim, Sanayi ve Teknoloji Bakanlığı, Sanayi Genel Müdürlüğü, (2014). Otomotiv Sektörü Raporu.

Yurdakul, M. ve İç, Y. (2003). Türk Otomotiv Firmalarının Performans Ölçümü ve Analizine Yönelik TOPSIS Yöntemini Kullanan Bir Örnek Çalışma. Gazi Üniversitesi Mühendislik ve Mimarlık Fakültesi Dergisi, 18(1): 1-18.

Yükçü, S. ve Atağan, G. (2010). TOPSIS Yöntemine Göre Performans Değerleme. Muhasebe ve Finansman Dergisi, 45: 28-35. 